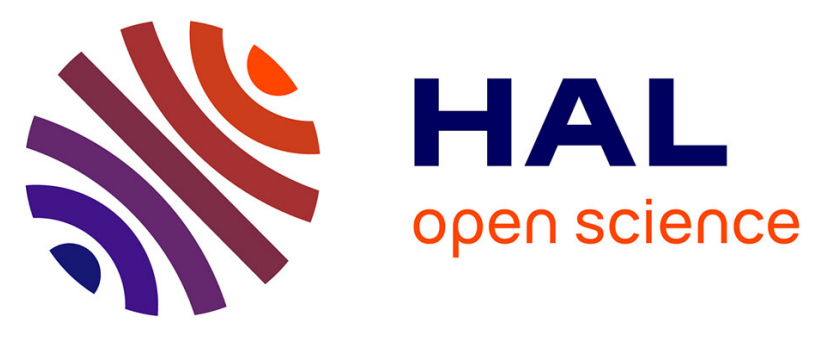

\title{
Conclusions of the French Food Safety Agency on the toxicity of bisphenol A
}

Nathalie Arnich, Marie-Chantal Canivenc-Lavier, Martine Kolf-Clauw, Hervé

Coffigny, Jean Pierre J. P. Cravedi, Konrad Grob, Anne-Christine Macherey, Dominique Masset, Rémi Maximilien, Jean-François Narbonne, et al.

\section{To cite this version:}

Nathalie Arnich, Marie-Chantal Canivenc-Lavier, Martine Kolf-Clauw, Hervé Coffigny, Jean Pierre J. P. Cravedi, et al.. Conclusions of the French Food Safety Agency on the toxicity of bisphenol A. International Journal of Hygiene and Environmental Health, 2011, 214 (3), pp.271-275. 10.1016/j.ijheh.2010.12.002 . hal-01594322

\section{HAL Id: hal-01594322 \\ https://hal.science/hal-01594322}

Submitted on 26 Sep 2017

HAL is a multi-disciplinary open access archive for the deposit and dissemination of scientific research documents, whether they are published or not. The documents may come from teaching and research institutions in France or abroad, or from public or private research centers.
L'archive ouverte pluridisciplinaire HAL, est destinée au dépôt et à la diffusion de documents scientifiques de niveau recherche, publiés ou non, émanant des établissements d'enseignement et de recherche français ou étrangers, des laboratoires publics ou privés. 


\title{
Conclusions of the French Food Safety Agency on the toxicity of bisphenol A
}

\author{
Nathalie Arnich $^{\mathrm{a}, *}$, Marie-Chantal Canivenc-Lavier ${ }^{\mathrm{b}}$, Martine Kolf-Clauw ${ }^{\mathrm{c}}$, Hervé Coffigny ${ }^{\mathrm{d}}$, \\ Jean-Pierre Cravedi ${ }^{\mathrm{e}}$, Konrad Grob ${ }^{\mathrm{f}}$, Anne-Christine Macherey ${ }^{\mathrm{g}}$, Dominique Masset ${ }^{\mathrm{h}}$, \\ Rémi Maximilien ${ }^{\mathrm{d}}$, Jean-François Narbonne ${ }^{\mathrm{i}}$, Fabrice Nesslany ${ }^{\mathrm{j}}$, Jeanne Stadler ${ }^{\mathrm{k}}$, Jacques Tulliez ${ }^{\mathrm{e}}$ \\ a AFSSA - Agence Française de Sécurité Sanitaire des Aliments, Maisons-Alfort, France \\ ${ }^{\mathrm{b}}$ INRA - Institut National de la Recherche Agronomique, Dijon, France \\ ${ }^{\mathrm{c}}$ ENVT - Ecole Nationale Vétérinaire, Toulouse, France \\ ${ }^{\mathrm{d}}$ CEA - Commissariat à l'Énergie Atomique, Fontenay-aux-Roses, France \\ e INRA - Institut National de la Recherche Agronomique, Toulouse, France \\ f Official Food Control Authority of the Canton of Zurich, Switzerland \\ g CNRS - Unité de Prévention du Risque Chimique, Gif-sur-Yvette, France \\ h AFSSaPS - Agence Française de Sécurité Sanitaire des Produits de Santé, Saint-Denis, France \\ i Laboratoire de Toxicologie Biochimique, Université Bordeaux I, France \\ j IPL - Institut Pasteur Lille, France \\ ${ }^{\mathrm{k}}$ Toxicology Consultant, Tour, France
}

\section{A R T I C L E I N F O}

\section{Article history:}

Received 16 November 2010

Received in revised form 3 December 2010

Accepted 7 December 2010

\section{Keywords:}

Bisphenol A

BPA

Risk assessment

Toxicity

Endocrine disruptors

\begin{abstract}
A B S T R A C T
Since more than 10 years, risk assessment of bisphenol A (BPA) is debated at the international level. In 2008, the U.S. National Toxicology Program (NTP) expressed some concern for adverse effects, at current level of exposure to BPA, on developmental toxicity. In this context, the French Food Safety Agency (AFSSA) decided to review the toxicity data on BPA with a special focus on this endpoint at doses below $5 \mathrm{mg} / \mathrm{kg} \mathrm{bw} /$ day (the no observed adverse effect level set by different regulatory bodies). This paper summarizes the conclusions of a collective assessment conducted by an expert Working Group from AFSSA. Studies were classified into 3 groups: (i) finding no toxicity, (ii) reporting results not considered to be of concern and (iii) indicating warning signals. The term "warning signal" means that no formal conclusion can be drawn regarding the establishment of a health based guidance value but the study raises some questions about the toxicity of BPA at low doses. It was concluded that studies are needed to ascertain the significance for human health of these warning signals and to be able to propose new methodologies for assessing the risks associated with low doses of BPA and more generally of endocrine disruptors.
\end{abstract}

(c) 2011 Elsevier GmbH. All rights reserved.

\section{Introduction}

Bisphenol A [2,2-bis(4-hydroxyphenyl)propane] is used for many years as a monomer to produce (via polymerisation) polycarbonate and epoxy resins for coatings. Rigid and transparent polycarbonates are used in numerous food containers, such as reusable water bottles, baby bottles, tableware (plates and cups) and storage containers. Epoxy coatings are used inside food cans, pipes and tanks for drinking water and food industry.

In Europe, the tolerable daily intake (TDI) for BPA is $0.05 \mathrm{mg} / \mathrm{kg}$ body weight (bw)/day. It has been set by the European Food Safety Authority (EFSA) in 2006 (and confirmed in 2010) based on a No Observed Adverse Effects Level (NOAEL) of $5 \mathrm{mg} / \mathrm{kg} \mathrm{bw} /$ day derived

\footnotetext{
* Corresponding author at: ANSES, 27-31 avenue du Général Leclerc, 94701 Maisons-Alfort, France. Tel.: +331497738 61; fax: +33149771352.

E-mail address: nathalie.arnich@anses.fr (N. Arnich).
}

from liver toxicity in a two-generation reproductive toxicity study in mice (Tyl et al., 2008) and using an uncertainty factor of 100 (EFSA, 2006, 2008, 2010) based on liver toxicity and using an uncertainty factor of 100 . However, several studies suggest various effects at doses lower than $5 \mathrm{mg} / \mathrm{kg}$ bw/day. The starting point was the conclusion of the U.S. National Toxicology Program (NTP, 2008) which expressed some concern for adverse effects, at current level of exposure to BPA, on developmental toxicity for fetuses, infants and children (effects on the brain, behaviour and prostate gland). Such results lead to controversy on the risk assessment of BPA with opposite statements between those considering that there is no risk at the current levels of exposure and those acknowledging a risk even at very low levels, especially for babies, related to the weak estrogenic activity of BPA.

To establish if previous assessments performed by AFSSA on BPA should be updated regarding toxicity of this compound (AFSSA, 2008a,b, 2009), the French Agency decided to perform a thorough review of a recent rat dietary neurodevelopmental toxicity study 
(Stump, 2009), complying with international guideline standards from OECD and U.S. EPA and designed to detect morphological and functional abnormalities (learning, memory, etc) from birth to adulthood. Other recently published data on the toxic effects of BPA and on the human exposure to this compound were also included. AFSSA set an ad hoc Working Group (WG) to perform this review through a collective assessment. This paper reports the key points of this work on the most relevant toxicity studies of BPA. The detailed assessment and comments are available in AFSSA's Opinion dated 29 January 2010 on the critical analysis of the results of a developmental neurotoxicity study of bisphenol A together with other recently published data on its toxic effects and in its Annex dated 31 May 2010 (AFSSA, 2010a,b).

\section{Methods}

AFSSA set a Working Group (WG) constituted of experts from three different scientific panels (on Food Contact Materials, on Residues and Physico-Chemical Contaminants in Food, on Pesticides), and one external expert experienced in BPA and endocrine disruptors. All the experts who are members of scientific panels were selected based on their scientific competence, their expertise and their declared interests by a specific board constituted of independent external evaluators and of AFSSA staff. Their declarations of interests are available on AFSSA's website. The external expert has been selected according to its specific competences and signed a declaration of interests before the start of the WG. Moreover, AFSSA has developed guidelines of good practice for risk assessment to guide the work of its experts. The opinions and reports are the outcome of collective deliberations, each expert is invited to express its view and minority positions are recorded.

The WG on BPA focused its work on published in vivo toxicity studies, with special interest for those assessing effects at low doses, and mainly on behavioural and reproductive effects. Studies on human biomonitoring and exposure were also considered, but not in vitro studies. The goal was not to be exhaustive but to analyze the studies that seemed to be most relevant for a dietary risk assessment.

Literature searched has been performed mainly by MEDLINE/PubMed and SCOPUS using "bisphenol A" in all fields (title, abstract, text), restricted to the mid-2009 to January 2010. Few older references were added to ensure a complete understanding of the recent data when needed. Review papers submitted by a French NGO, which has been invited to present its view, were also taken into account.

Methodological aspects (route of exposure, number of animals per group, number of doses, dose levels, use of positive controls, etc.), housing conditions of animals (use of polycarbonate drinking bottle, choice of bedding, presence of phytoetrogens in diet, etc.) along with the consistency of the results of each study were summarized and commented by the experts. Each study was reviewed by at least two experts and discussed collectively during meetings of the WG. The overall quality of the studies was quoted according to the criteria proposed by Klimish et al. (1997) for assessing reliability, relevance, and adequacy of data.

The conclusions of the WG were discussed and adopted by two scientific panels of the French Agency (Food Contact Materials and Residues and Physico-Chemical Contaminants in Food).

\section{Results and discussion}

The WG identified 52 relevant studies among which 28 were dedicated to BPA toxicity (experimental studies or review papers) and 24 were related to human exposure (release from baby bottles, cans, and biomonitoring data). The toxicity studies were catego- rized by the WG as (i) finding no toxicity, (ii) reporting results not considered to be of concern and (iii) indicating warning signals. The term "warning signal" means that no formal conclusion can be drawn regarding the establishment of a health based guidance value but the study raises some questions about the toxicity of BPA at low doses.

\section{Studies finding no toxicity of BPA}

The Stump's study (2009), complying with international guideline standards from OECD and U.S. EPA, was performed in rat pups born from dams orally treated at $0.15,1.5,75,750$, and $2250 \mathrm{mg} / \mathrm{kg}$ diet per day. Results did not show any effect on auditory startle, motor activity, learning and memory using the Biel water maze, brain and nervous system neuropathology, brain morphometry. The author set the NOAEL at $75 \mathrm{mg} / \mathrm{kg}$ diet (equivalent to $5.85 \mathrm{mg} / \mathrm{kg}$ bw/day) based on reduced maternal and offspring body weights.

In rat pups from dams treated by gavage at 2,20 or $200 \mu \mathrm{g} / \mathrm{kg}$ bw/day, Ryan et al. (2010) did not notice any effect on female anogenital distance, pups bodyweights, age at vaginal opening, F1 fertility, F2 litter sizes, malformations, female saccharin preference and lordosis behaviour. In addition, Howdeshell et al. (2008), in the same study performed in males, did not observe any effect on male anogenital distance, pups body weights, androgen-dependent tissue weights and epididymal sperm counts.

\section{Studies reporting results not considered to be of concern}

The following studies analyzed by the WG were not considered relevant for risk assessment because of major methodological flaws, the lack of consistency in the results, the overall poor quality of the protocol or because the conclusions given by the authors were not totally supported by the data.

Bosquiazzo et al. (2010) studied the effects of the subcutaneous administration of BPA ( 0.05 or $20 \mathrm{mg} / \mathrm{kg}$ bw/day) in newborn female rats, treated between postnatal days 1 and 7, on steroid regulation of vascular growth factor expression and endothelial cell proliferation in the adult rat uterus ( $>90$ days of age). The results of this study were not considered of concern because of major methodological flaws and the non relevance of the route of administration for dietary risk assessment. In addition, it was noticed that rats were ovariectomized at 80 days of age and submitted to hormonal replacement before uterine tissues were sampled.

Braun et al. (2009) examined the potential association between prenatal BPA exposure and behaviour in young children based on data from 249 mothers and their children. Prenatal exposure to BPA was assessed through maternal urine collected between weeks 16 and 26 of pregnancy and at birth. Child behaviour was assessed at 2 years of age using the second edition of the Behavioural Assessment System for Children (BASC-2), a 134-item parent-reported assessment of a child's adaptive and problematic behaviours in community and home settings. The test is declined for three age levels: preschool (ages 2-5), child (ages 6-11), and adolescent (ages 12-21). The authors concluded that prenatal exposure to BPA may be associated with externalizing behaviours in 2-year-old children, especially among females. However, numerous methodological flaws were underlined by the WG. With respect to exposure assessment, some urine samples were stored up to 5 years before analysis, whereas stability of BPA in frozen urine was not demonstrated for such a long time. Regarding the BASC-2, the authors used the lowest limit of validity of the test (2 years). Scores were normalized to a mean $( \pm$ SD) of $50 \pm 10$ during the national (U.S.A.) standardization of the instrument. Scores in the 60-69 range are considered "at risk," and scores $\geq 70$ are considered clinically significant. The results of this study were not considered of concern by the WG, 
since highest adjusted mean score was 53.9, e.g. within the range of average responses that are indicative of normal behaviour (41-59). Moreover Longnecker (2009) also expressed some reservation on the results of this study: although the sexual dimorphism of externalizing behaviour is widely recognized, absolute differences in externalized scores associated with BPA cannot be determined using the sex-standardized data presented.

Fernández et al. (2009) investigated the effects of BPA exposure during the 10 first days of life on reproductive parameters and the gonadotropin releasing hormone signaling in female rats, combining in vivo and in vitro assays (on cells from animals treated with BPA). The results of this study were not considered of concern by the WG because of major methodological flaws, such as the non relevance of the route of administration (subcutaneous) and because most of the effects were only observed at the highest dose ( $500 \mu \mathrm{g} / 50 \mu \mathrm{L}$, approximately equivalent to $25-62 \mathrm{mg} / \mathrm{kg} \mathrm{bw})$, which is far above the NOAEL of $5 \mathrm{mg} / \mathrm{kg}$ bw/day used for deriving the current TDI.

Izzotti et al. (2009) measured DNA adducts in liver and mammary cells of female mice receiving BPA in drinking water ( $200 \mathrm{mg} / \mathrm{kg}$ bw) for 8 days. Levels of DNA adducts were very low according to the high dose tested and were therefore not considered of concern by the WG.

Li et al. (2010) concluded that BPA-exposed workers exhibited higher risk of male sexual dysfunction than unexposed workers (reduced sexual desire, erectile difficulty, ejaculation difficulty and reduced satisfaction with sex life). However, data were obtained by self-reporting, without supporting clinical data and can consequently be questioned. In addition, occupational exposure mainly took place through inhalation, which is of limited value for the general population, orally exposed to lower doses of BPA.

Monje et al. (2009) studied the effects of BPA exposure ( 0.05 or $20 \mathrm{mg} / \mathrm{kg} \mathrm{bw}$ ) during the seven first days of life on hypothalamic estrogen-dependent mechanisms that govern sexual behaviour in the adult female rat. Behavioural parameters were measured in only 5 animals tested 2 times over a 2 -week period and tests were performed for $10 \mathrm{~min}$ or 10 mounts (which ever occurred first) via videotape based on lordosis, ear wiggling, hopping, and darting during the test. In addition, rats were ovariectomized at 85 days of age and the route of administration (subcutaneous) was not relevant. Consequently, results of this study were not considered of concern.

Sargis et al. (2010) investigated effects of BPA on adipogenesis in vitro using the 3T3-L1 cell line. This study performed in vitro was exceptionally included in the review because the French NGO considers this study as being of high interest. No detectable adipogenesis occurred when the preadipocytes were treated with BPA alone. The promotion of adipocyte differentiation took place only when dehydrocorticosterone (an agent of cell differentiation) was added. Therefore, the results of this study were not considered of concern.

Somm et al. (2009) evaluated the effects of BPA in drinking water ( $1 \mathrm{mg} / \mathrm{l}$, equivalent to $70 \mu \mathrm{g} / \mathrm{kg}$ bw/day) on early adipose storage in weaned rats following exposure of dams during gestation and lactation. Results suggest that perinatal exposure to BPA could increase body weight. Although there are several limitations in this study (limited number of litters, only one dose tested, interpretation based on the pup instead of the litter), the WG agreed with the authors that further studies are required to understand the mechanisms of action.

\section{Studies indicating warning signals}

Studies considered as warning signals show subtle effects on behaviour, reproductive tract or intestine and effects on reproduction or the reproductive tract. However, there are major methodological flaws in these studies, as underlined below.

\section{Subtle effects on behaviour}

Following perinatal subcutaneous exposure of female monkeys to $10 \mu \mathrm{g} / \mathrm{kg}$ bw/day of BPA during gestation and suckling, Nakagami et al. (2009) observed the alteration of 3 out of 14 behaviours in pups, namely clinging, outward looking and social exploration. In a review of several studies performed by their team in mice orally exposed to $10 \mu \mathrm{g} / \mathrm{kg}$ bw/day of BPA, Palanza et al. (2008) concluded that dams spent less time nursing and more time resting alone (mainly based on data from Gioiosa et al., 2007). However, no effects on weaning weight were shown, suggesting an adequate level of maternal care. In offspring, the authors indicated a reduction or elimination of the sex difference in behaviour (namely curiosity and anxiety). The relevance of these effects in terms of human health has not yet been established.

\section{Subtle effects on the reproductive tract}

Following perinatal exposure of rats to BPA by gavage (1.2 or $2.4 \mu \mathrm{g} / \mathrm{kg}$ bw/day) Salian et al. (2009a) noticed changes in the expression of steroid receptor coregulators in the testis. The effects persisted through 3 generations, whereas only F1 pups were exposed in utero and during suckling. In neonatal rats (1-5 postnatal day) subcutaneously treated with BPA doses ranging from 100 to $1600 \mu \mathrm{g} / \mathrm{kg}$ bw/day, Salian et al. (2009b) observed changes in expression of Sertoli cell junctional proteins during juvenile and adult life. But, the relevance of these effects in terms of human health remains to be established.

\section{Subtle effects on intestine}

In ovariectomized rats orally exposed to 0.05 or $5 \mathrm{mg} \mathrm{BPA} / \mathrm{kg}$ diet per day, Braniste et al. (2010) observed on the one hand a decrease of the basal colonic paracellular permeability and on the other hand an increase in epithelial tight junction sealing and in pain sensitivity to colorectal stimuli. Following in utero and suckling exposure through dams treated by gavage to $5 \mathrm{mg} / \mathrm{kg} /$ day, the basal colonic paracellular permeability is decreased and the proinflammatory response of colonic mucosa is increased in adults (only in females). The limited number of doses tested in this study makes its use difficult for risk assessment. The relevance of these effects in terms of human health remains to be established.

\section{Effects on reproduction and reproductive tract}

In rats following oral exposure of dams by gavage to 1.2 or $2.4 \mu \mathrm{g}$ $\mathrm{BPA} / \mathrm{kg}$ bw/day, Salian et al. (2009c) observed an increased post implantation loss, a decreased litter size, sperm count and motility in F1 male offspring. Following subcutaneous exposure of neonatal rats (postnatal days 1-5) from 100 to $1600 \mu \mathrm{g} \mathrm{BPA} / \mathrm{kg}$ bw/day, Salian et al. (2009b) also observed a similar increase in post implantation loss, a decrease in litter size and a change in sperm count with, in addition, changed hormonal balances.

In rat from dams subcutaneously treated with BPA $(2.5-1000 \mu \mathrm{g} / \mathrm{kg}$ bw/day) during gestation, Murray et al. (2007) observed the development of ductal hyperplasias and of carcinomas of the mammary gland.

In mice from dams subcutaneously treated (gestational days 9-16) to $0.1-1000 \mu \mathrm{g}$ BPA $/ \mathrm{kg}$ bw/day, Newbold et al. (2009) observed an increase in ovarian cysts, in progressive proliferative lesions of the oviduct and in tumor incidence of reproductive tissues.

The WG concluded that these studies should be considered as warning signals because of the limited number of doses tested in these studies and/or the inappropriate route of administration (subcutaneous) that make their use difficult for risk assessment. 
Comments on the major flaws of the studies indicating warning signals

The majority of the above-mentioned studies indicating warning signals have strong limitations impeding conclusion in terms of dietary risk assessment:

- The route of administration is not oral but subcutaneous (Nakagami et al., 2009; Murray et al., 2007; Newbold et al., 2009; Salian et al., 2009b).

- Only one dose was tested, namely $10 \mu \mathrm{g} / \mathrm{kg}$ bw/day (Palanza et al., 2008; Nakagami et al., 2009) and $5 \mathrm{mg} \mathrm{kg/bw/day} \mathrm{(Braniste} \mathrm{et} \mathrm{al.,}$ 2010 for perinatal exposure). Consequently, no dose-response relationship can be established.

- The effects are observed in ovariectomized rat (Braniste et al., 2010) and are not easy to be extrapolated to humans.

- No positive control were used (all studies, except Salian et al., 2009b,c; Braniste et al., 2010).

- No data on actual exposure of the offspring were provided (for all oral studies). Rats exhibiting effects are indirectly exposed through the dam during gestation and suckling, whereas the BPA level in rat milk is not known.

- The diet could be a source of bias because of the presence of phytoestrogens in soy-based diet (Palanza et al., 2008), because it is an in-housed prepared diet (Salian et al., 2009a,b,c) or because no data are provided on the potential presence of endocrine disruptors in feed (Nakagami et al., 2009).

- Similarly, no data are provided on the level of endocrine disruptors in the bedding (Braniste et al., 2010). Such data could be of upmost importance when the bedding is composed of corn cob (Palanza et al., 2008), puddy husk (Salian et al., 2009a,b,c) or hardwood chip (Newbold et al., 2009).

- The use of polycarbonate bottles for rat drinking water (Newbold et al., 2009) could be a source of BPA.

\section{Conclusions of the Working Group}

So far, toxicity studies on BPA performed in compliance with international standards have not demonstrated any risk to human health at the current levels of exposure. Other studies, performed according to various protocols, observed effects following in utero and postnatal exposures at doses lower than $5 \mathrm{mg} / \mathrm{kg}$ bw/day. However, these studies have major flaws and/or the relevance on human health of the effects has not yet been demonstrated. Consequently, such data were interpreted by the French Agency as warning signals. Furthermore, it is clearly essential to understand the mechanisms of action of these warning signals, to establish if they are associated with the oestrogenic activity of BPA, since humans are also exposed to other estrogenic compounds in food, both from chemical and natural origins. In this case, BPA should not be considered alone, but as part of a mixture of endocrine active substances.

On the other hand, sources of exposure to BPA other than food contact materials should be more thoroughly investigated, as they might be critical for consumers and for supporting the authorities to take appropriate measures.

In the meantime, the German Institute for Risk Assessment (BfR, 2010) and the DTU Fødevareinstituttets (2010) published updates on BPA, including comments on the study by Stump (2009). The BfR concluded that the results of this study (along with Ryan et al., 2010) do not substantiate the concerns for a specific toxic potential of BPA adverse to neurological and behavioural development. However, the DTU stated that the Stump's study gives rise to a degree of uncertainty with regard to the effects on learning ability, since impaired learning ability was found in male offspring with a low dosage of BPA. The significance of the results on impaired learning ability was not confirmed by the European Food Safety Authority (EFSA) after a statistical re-analysis of data (EFSA, 2010). Following a review of recent scientific literature and studies on the toxicity of BPA at low doses, EFSA also concluded that there was no new evidence which would lead to revise the current TDI for BPA of $0.05 \mathrm{mg} / \mathrm{kg}$ body weight and that the data currently available do not provide convincing evidence of neurobehavioural toxicity of BPA. Regarding the studies that report adverse effects on animals exposed to BPA during development at doses well below those used to determine the current TDI, EFSA concluded, in agreement with AFSSA, that they have many shortcomings. The European Authority did not interpret these data as warning signals but acknowledged that the relevance of these findings for human health needs further work. At the international level, the World Health Organization (WHO) and the Food and Agriculture Organization of the United Nations (FAO) jointly organized an expert meeting in November 2010 to review toxicological and health aspects of bisphenol A. The expert meeting came to the same conclusion that there is no health concern for many end-points. However, findings on emerging new end-points should drive the direction of future research with the objective of reducing uncertainty.

Derived from the case of BPA, the French experts issued the following recommendations for toxicity studies and risk assessment associated with endocrine disruptors.

Studies designed to establish toxicological reference values (as detailed in guidelines for regulatory toxicology tests) should include:

- toxicokinetic parameters and particularly plasma and/or urine concentrations to express internal doses especially in case of indirect exposure through suckling;

- hormonal analysis (concentrations of hormones and their metabolite(s) in blood and urine);

- investigation on the effects on physiological functions identified as critical, depending on the development stage at the time of exposure;

- consideration of methodological bias, such as the effects of diet (e.g. the presence of phytoestrogens in soy-based products), polycarbonate materials, the composition of the drinking water given to the animals, the bedding (which may contain mycotoxins, terpenes, polyphenols, etc.).

- Several doses, including low doses, should be tested in order to determine a dose-response relationship.

Moreover, the WG concluded that the assessment of potential health risks associated with low levels of endocrine disruptors presupposes a new methodology. Indeed, such compounds can have different effects depending on the development stage (critical exposure windows during which adverse effects can appear, especially the perinatal period). In this context, the relevance of the Tolerable Dietary Intake approach for risk assessment could be questioned. By definition, the TDI is the maximum quantity of a compound that can be consumed daily over an entire lifetime without the risk of harmful effects on human health. The WG noted that risk assessment of endocrine disruptors is especially complicated due to:

- the nature of effects caused by compounds interacting with the endocrine system;

- the nature of subtle effects in terms of human health, which significance has to be established: sex difference in behaviour of offspring (curiosity, anxiety, social exploration, clinging, outward looking), time dams spent nursing, changes in expression of coregulators or proteins, intestinal permeability/pain sensitivity, $\ldots$; 
- suggested non-monotonic dose-response relationship;

- potential lack of a threshold for effect;

- effects at very low doses;

- exposure window: adverse effects following exposure on immature systems;

- potential delayed effects.

In the meantime, the calculation of margins of exposure (MOE) could be used as a tool for prioritizing endocrine disruptors. Margins would be estimated based on the Lowest Observed Adverse Effect Level (LOAEL) in the most sensitive animal species or human data on the one hand, and the estimated human exposure on the basis of dietary intake or biomonitoring data for different subpopulations (pregnant women, infant, young children, adults) on the other. This approach avoids the need to determine a safety factor $a$ priori and allows taking into account the specific sensitivity of humans at different stage of life by using different LOAELs. However, this approach cannot be applied to bisphenol A before the significance of the warning signals has been clearly established. In conclusion, the mobilization of scientists at international level is necessary to reach this goal, through the collaboration of academic researchers and governmental bodies.

\section{Toxicity studies reviewed}

Bosquiazzo, V.L., Varayoud, J., Muñoz-de-Toro, M., Luque, E.H., Ramos, J.G., 2010. Effects of neonatal exposure to bisphenol A on steroid regulation of vascular endothelial growth factor expression and endothelial cell proliferation in the adult rat uterus. Biol. Reprod. 82 (1), 86-95.

Braniste, V., Jouault, A., Gaultier, E., Polizzi, A., Buisson-Brenac, C., Leveque, M., Martin, P.G., Theodorou, V., Fioramonti, J., Houdeau, E., 2010. Impact of oral bisphenol $A$ at reference doses on intestinal barrier function and sex differences after perinatal exposure in rats. Proc. Natl. Acad. Sci. U.S.A. 107 (1), 448-453.

Braun, J.M., Yolton, K., Dietrich, K.N., Hornung, R., Ye, X., Calafat, A.M., Lanphear, B.P., 2009. Prenatal bisphenol A exposure and early childhood behavior. Environ. Health Perspect. 117 (12), 1945-1952.

Fernández, M., Bianchi, M., Lux-Lantos, V., Libertun, C., 2009. Neonatal exposure to bisphenol A alters reproductive parameters and gonadotropin releasing hormone signaling in female rats. Environ. Health Perspect. 117, 757-762.

Howdeshell, K.L., Furr, J., Lambright, C.R., Wilson, V.S., Ryan, B.C., Gray Jr., L.E., 2008. Gestational and lactational exposure to ethinyl estradiol, but not bisphenol $\mathrm{A}$, decreases androgen-dependent reproductive organ weights and epididymal sperm abundance in the male long evans hooded rat. Toxicol. Sci. 102 (2), 371-382.

Izzotti, A., Kanitz, S., D’Agostini, F., Camoirano, A., De Flora, S., 2009. Formation of adducts by bisphenol A, an endocrine disruptor, in DNA in vitro and in liver and mammary tissue of mice. Mutat. Res. $679(1 / 2), 28-32$.

Li, D., Zhou, Z., Qing, D., He, Y., Wu, T., Miao, M., Wang, J., Weng, X., Ferber, J.R., Herrinton, L.J., Zhu, Q., Gao, E., Checkoway, H., Yuan, W., 2010. Occupational exposure to bisphenol-A (BPA) and the risk of self-reported male sexual dysfunction. Hum. Reprod. 25 (2), 519-527.

Monje, L., Varayoud, J., Munoz-de-Toro, M., Luque, E.H., Ramos, J.G., 2009. Neonatal exposure to bisphenol A alters estrogen-dependent mechanisms governing sexual behavior in the adult female rat. Reprod. Toxicol. 28 (4), 435-442.

Murray, T.J., Maffini, M.V., Ucci, A.A., Sonnenschein, C., Soto, A.M., 2007. Induction of mammary gland ductal hyperplasias and carcinoma in situ following fetal bisphenol A exposure. Reprod. Toxicol. 23, 383-390.

Nakagami, A., Negishi, T., Kawasaki, K., Imai, N., Nishida, Y., Ihara, T., Kuroda, Y., Yoshikawa, Y., Koyama, T., 2009. Alterations in male infant behaviors towards its mother by prenatal exposure to bisphenol A in cynomolgus monkeys (Macaca fascicularis) during early suckling period. Psychoneuroendocrinology 34, 1189-1197.

Newbold, R.R., Jefferson, W.N., Padilla-Banks, E., 2009. Prenatal exposure to bisphenol $\mathrm{A}$ at environmentally relevant doses adversely affects the murine female reproductive tract later in life. Environ. Health Perspect. 117, 879-885.

Palanza, P., Gioiosa, L., vom Saal, S.F., Parmigiani, S., 2008. Effects of developmental exposure to bisphenol A on brain and behavior in mice. Environ. Res. 108, $150-157$.
Ryan, B.C., Hotchkiss, A.K., Crofton, K.M., Gray, E.A., 2010. In utero and lactational exposure to bisphenol $\mathrm{A}$, in contrast to ethinyl estradiol, does not alter sexually dimorphic behavior, puberty, fertility and anatomy of female LE rats. Toxicol. Sci. 114 (1), 133-148.

Salian, S., Doshi, T., Vanage, G., 2009a. Impairment in protein expression profile of testicular steroid receptor coregulators in male offspring perinatally exposed to bisphenol A. Life Sci. 85, 11-18.

Salian, S., Doshi, T., Vanage, G., 2009b. Neonatal exposure of male rats to bisphenol A impairs fertility and expression of sertoli cell junctional proteins in the testis. Toxicology $265(1 / 2), 56-67$.

Salian, S., Doshi, T., Vanage, G., 2009c. Perinatal exposure of rats to bisphenol A affects the fertility of male offspring. Life Sci. 85 (21/22), 742-752.

Sargis, R.M., Johnson, D.N., Choudhury, R.A., Brady, M.J., 2010. Environmental endocrine disruptors promote adipogenesis in the 3T3-L1 cell line through glucocorticoid receptor activation. Obesity 118, 1283-1288.

Somm, E., Schwitzgebel, V.M., Toulotte, A., Cederrroth, C.R., Combescure, C., Nef, S., Aubert, M.L., Hüppi, P., 2009. Perinatal exposure to bisphenol a alters early adipogenesis in the rat. Environ. Health Perspect. 117, 1549-1555.

Stump, D.G., 2009. A Dietary Developmental Neurotoxicity Study of Bisphenol in Rats, WIL-186056, 4796 pp. (September).

\section{Supporting references}

AFSSA, 2008a. Opinion of 24 October 2008 regarding bisphenol A in polycarbonate baby bottles likely to be heated in a microwave ovens (available from www.anses.fr).

AFSSA, 2008b. Opinion of 21 November 2008 regarding the exposure assessment of bisphenol $A$ in water intended for human consumption and possible resulting health risks.

AFSSA, 2009. Memorandum of 7 July 2009 regarding the pubmication by Stahlhut et al. (2009) on urinary elimination of bisphenol A in humans.

AFSSA, 2010a. Opinion of 29 January 2010 on the critical analysis of the results of a developmental neurotoxicity study of bisphenol A together with other recentlypublished data on its toxic effects.

AFSSA, 2010b. Annex of 31 May 2010 to the opinion of 29 January 2010 on the critical analysis of the results of a developmental neurotoxicity study of bisphenol A together with other recently-published data on its toxic effects.

BfR (Bundesinstitut für Risikobewertung), 2010. Bisphenol A: studies by Stump et al. (2010) and Ryan et al. (2010) provide no indications for adverse effects on neurological development and behaviour (available from http://www.bfr.bund.de/ cm/290/bisphenol_a_studys_by_stump_et_al_2010_and_ryan_et_al_2010.pdf).

DTU Fødevareinstituttets, 2010. Evaluation by the DTU Food Institute of the industry's new developmental neurotoxicity study (DNT, OECD TG 426) of bisphenol A and the significance of the study for the Food Institute's assessment of the potential harmful effects of bisphenol A on the development of the nervous system and behavior (available from: http://www.food.dtu.dk/ Admin/Public/Download.aspx?file=Files\%2fFiler\%2fNyheder\%2fVurdering_BPAstudie.pdf).

EFSA, 2006. Opinion of the scientific panel on food additives, flavourings, processing aids and materials in contact with food on a request from the commission related to 2,2-BIS(4-hydroxyphenyl)propane (bisphenol A) question number EFSA-Q2005-100, adopted on 29 November 2006. EFSA J. 428, 1-75.

EFSA, 2008. Toxicokinetics of bisphenol A. Scientific opinion of the panel on food additives, flavourings, processing aids and materials in contact with food (AFC), question number EFSA-Q-2008-382, adopted on 9 July 2008. EFSA J. 759, $1-10$.

EFSA, 2010. Scientific opinion on bisphenol A: evaluation of a study investigating its neurodevelopmental toxicity, review of recent scientific literature on its toxicity and advice on the Danish risk assessment of bisphenol A. EFSA J. 8 (9), 1829 (110 pp.).

Gioiosa, L., Fissore, E., Ghirardelli, G., Parmigiani, S., Palanza, P., 2007. Developmental exposure to low-dose estrogenic endocrine disruptors alterssex differences in exploration and emotional responses in mice. Horm. Behav. 52, 307-316.

Klimish, H.J., Andreae, M., Tillman, U., 1997. A systematic approach for evaluating the quality of experimental toxicological and ecotoxicological data. Regul. Toxicol. Pharm. 25, 1-5.

Longnecker, M.P., 2009. Human data on bisphenol A and neurodevelopment. Environ. Health Persp. 117 (12), A531-A532.

NTP, 2008. NTP-CERHR monograph on the potential human reproductive and developmental effects of bisphenol A, September 2008, NIH Publication No. 08-5994, $321 \mathrm{pp}$.

Tyl, R.W., Myers, C.B., Marr, M.C., Sloan, C.S., Castillo, N.P., Veselica, M.M., Seely, J.C., Dimond, S.S., Van Miller, J.P., Shiotsuka, R.N., Beyer, D., Hentges, S.G., Waechter Jr., J.M., 2008. Two-generation reproductive toxicity study of dietary bisphenol A in CD-1 (Swiss) mice. Toxicol. Sci. 104 (2), 362-384. 